BMJ Open

Diabetes

Research

\& Care

\title{
Health-related quality of life and its associated factors among adult patients with type II diabetes attending Mizan Tepi University Teaching Hospital, Southwest Ethiopia
}

\author{
Tadesse Gebremedhin, ${ }^{1}$ Abdulhalik Workicho, ${ }^{2}$ Dessie Abebaw Angaw ${ }^{2}$
}

\begin{abstract}
To cite: Gebremedhin T, Workicho A, Angaw DA. Health-related quality of life and its associated factors among adult patients with type II diabetes attending Mizan Tepi University Teaching Hospital, Southwest Ethiopia. BMJ Open Diab Res Care 2019;7:e000577. doi:10.1136/ bmjdrc-2018-000577
\end{abstract}

Received 2 August 2018 Revised 8 November 2018 Accepted 17 December 2018

A Check for updates

(c) Author(s) (or their employer(s)) 2019. Re-use permitted under CC BY-NC. No commercial re-use. See rights and permissions. Published by BMJ.

${ }^{1}$ Department of Public Health, Mizan Aman College of Health Science, Addis Ababa, Ethiopia ${ }^{2}$ Department of Epidemiology, Institute of Health, Faculty of Public Health, University of Jimma, Addis Ababa, Ethiopia

Correspondence to Dessie Abebaw Angaw; dessieabebaw96@gmail.com

\section{ABSTRACT}

Background Health-related quality of life (HRQOL) has become an important measure for evaluating patient treatment with non-curable chronic disease. The aim of the study was to assess HRQOL and its associated factors among patients with type II diabetes.

Methods This is an institution-based, cross-sectional study conducted from March 13 to May 9, 2018. A total of 267 patients with type II diabetes who visited the clinic for follow-up for at least 3 months and who were 18 years or older were included in the study. The WHO Quality of LifeBREF was used to assess quality of life. Multivariable linear regression was employed to identify associated factors with HRQOL among patients with type II diabetes. Results The mean score for overall HRQOL was $51.50 \pm 15.78$. The mean scores for physical health, psychological, environmental and social relationship domains were $49.10 \pm 18.14,53.51 \pm 19.82,49.72 \pm 16.09$ and $53.68 \pm 17.50$, respectively. Age, disease duration and fasting blood glucose level were inversely associated with all domains of HRQOL $(p<0.001)$. Body mass index was inversely related with all domains of HRQOL except with the physical health domain.

Conclusion The findings from this study indicated that all dimensions of HRQOL of patients with diabetes in this study setting were compromised. The study also identified important predictors such as age, duration of disease and level of fasting blood sugar. This entails the need to intervene in improving the HRQOL of patients with diabetes beyond the provision of standard treatments.

\section{INTRODUCTION}

Diabetes is a serious chronic disease that occurs either when the pancreas does not produce enough insulin or when the body cannot effectively use the insulin it produces. Diabetes is one of the largest global health emergencies of the 21st century and is associated with changes in lifestyle resulting in less physical activity and increased obesity. ${ }^{1}{ }^{2}$ The age-adjusted death rate of diabetes mellitus (DM) is 22.62 per 100 000 of the population and it ranks 98th in the world. ${ }^{3}$ It can gradually develop complications

\section{Significance of this study}

What is already known about this subject?

- The WHO and International Diabetic Federation recommended that HRQOL measurement as a major interventional outcome, and

- HRQOL and associated factors in several studies were focused on overall HRQOL.

What are the new findings?

- All dimensions of HRQOL among patients with diabetes in this study setting were compromised.

- All domains of HRQOL were inversely associated with duration of disease, age of patients and fasting blood sugar.

- This study identified specific factors for each domain in addition to overall HRQOL.

- This study revealed that body mass index and number of complications are inversely associated with overall HRQOL.

\section{How might these results change the focus of} research or clinical practice?

- This finding provides insight to focus on HRQOL for measure of interventions among patients with non-curative diseases.

- This finding will improve client-physician communication.

- The results of this study provide information to decision makers and program planners that will help develop, monitor, and evaluate treatment strategies and existing treatment guidelines for patients with type II diabetes.

and is known to be associated with an increased cardiovascular risk. It can reduce quality of life and life expectancy. ${ }^{45}$

WHO defines quality of life as an "individual's perception of their position in life in the context of the culture and value systems in which they live and in relation to their goals, expectations, standards and concerns". Health-related quality of 
life (HRQOL) refers to the physical, psychological, and social domains of health that are influenced by a person's experiences, beliefs, expectations, and perceptions; therefore, healthcare providers should strive to understand the physical, emotional, and social impact of chronic diseases such as DM. ${ }^{67}$ Diabetes has a significant negative impact on social relationship, life expectancy, academic performance and overall HRQOL of patients as a result of long-term microvascular and macrovascular complications. ${ }^{1458}$

HRQOL has gained increased attention as an outcome measure of interventions and treatments in patients with chronic diseases. Most of health professionals in the world still focus on treatment, and are unaware of the social and economic impact of diabetes. They also have limited knowledge/information on their patients' subjective HRQOL profile. This lack of understanding is the biggest barrier to effective intervention strategies that could help halt the inexorable rise in type II diabetes. ${ }^{1}$

There is now extensive evidence that good management improves immediate and long-term HRQOL of those with type II diabetes. Measuring the HRQOL is one component of a good management of type II DM. ${ }^{15}$

Although healthcare providers provide adequate care/ support for severely ill patients with diabetes, patients' perception of quality of life may not match healthcare providers' view. Therefore, measuring HRQOL will help in monitoring treatment guidelines and improving patients' HRQOL. Analysis of HRQOL can identify groups with poor HRQOL, and this could guide interventions that will improve their situation and avert more serious consequences, allocate limited resources based on unmet need, guide strategic plan, and monitor the intervention given. ${ }^{910}$ Improving quality of life is an ultimate goal of the Centres for Disease Control and Prevention and an important outcome of all medical interventions in patients with diabetes. To improve HRQOL, healthcare providers should have knowledge on their patients' subjective perception of HRQOL. ${ }^{10}$

According to American Diabetes Association recommendations, HRQOL monitoring is a key measure for effective management and improved clinical outcomes. The American Diabetes Association also recommends that providers monitor the burden of treatment and life conditions of patients when prescribing treatments. In spite of these recommendations, glucose levels are poorly controlled and HRQOL of patients are still not well studied. ${ }^{511} 12$ It is known that diabetes causes poor blood glucose regulation, but the effect of the illness on individuals' social relationships, working capacity, and financial status has received little systematic attention. ${ }^{13}$

High burden of DM and its complications is prominent in the developing world, but studies are fewer than the developed world. Even though measuring HRQOL is a crucial input for decision makers and policy makers and also in the development of guidelines, to our knowledge in Ethiopia there is only one study on HRQOL in patients with DM, conducted in Jimma University Specialized Hospital, ${ }^{14}$ suggesting a paucity of evidence on the problem that will help make informed decision making. Thus, to fill this gap, we conducted this research with the main objective of determining the level of HRQOL and its associated factors among patients with type II diabetes attending the Mizan Tepi University Teaching Hospital in Southwest Ethiopia.

\section{METHODS}

\section{Study design and setting}

An institution-based, cross-sectional study was conducted between March 13 and May 9, 2018. The study was conducted at Mizan Tepi University Teaching Hospital, located in the Southern Nations, Nationalities and People's Regional State Government, in the Bench Maji Zone. It is $593 \mathrm{~km}$ southwest of Addis Ababa. Currently, the hospital has 419 patients with type II diabetes on follow-up. These patients have regular follow-up at least once per month. In addition, patients can visit the clinic when he/she needs care. Adult patients with type II diabetes attending the Mizan Tepi University Teaching Hospital who are 18 years or older and who visited the clinic for follow-up for at least three times participated in the study.

\section{Measurements}

Data were collected using the Amharic version of the WHO Quality of Life-BREF (WHOQOL-BREF) questionnaire. Four trained diploma nurses collected the data and two BSc nurses supervised the data collection activities. Variables such as treatment modality (oral hypoglycemic agent, insulin therapy, and both oral hypoglycemic and insulin), number of diabetes-related complications (confirmed before 1 month of data collection day), fasting blood sugar (records from the last three visits were taken) and presence of documented comorbidity (confirmed before 1 month of data collection period) were obtained from patients' medical records. Weight was measured to the nearest $0.5 \mathrm{~kg}$ and height was taken to the nearest 0.1 $\mathrm{cm}$. Socioeconomic-related variables such as marital status, educational status, occupational status, monthly income, and enrollment in community-based health insurance were also collected.

Duration of disease was determined from the time of diagnosis. Long-term diabetic complications, including diabetic retinopathy, nephropathy and neuropathy, were confirmed by the physician, and were taken from medical records and confirmed by the physician 1 month before the day of data collection. To assess medication adherence, we adapted the eight-item Morisky Medication Adherence Scale, which consists of yes/ no questions and with scores of $0-5$ for low adherence, $6-7$ for medium adherence and 8 for high adherence. ${ }^{15}$ Current substance user in this study was defined as an individual who consumed at least one of the substances 
such as alcohol, cigarette/tobacco and chat in the past 3 months.

\section{Sample size and sampling technique}

Among 417 adult patients with type II diabetes appointed for the next 1 month from initiation of data collection, 394 were eligible to be included in the study. Sample size was computed by taking a similar study from Ghana. ${ }^{16}$ We used the mean and SD of the overall HRQOL among patients with type II diabetes, being $56 \pm 8.23$; the margin of error was decided to be $1 \%$ at $95 \%$ confidence level. The software used to calculate the sample size is available at http://select-statistics.co.uk/calculators/sample-sizecalculator-population-mean/. The computed sample size was 261 and a $10 \%$ non-response rate was added. The final sample size was 287. Taking medical record numbers of eligible patients as the sampling frame, simple random sampling technique was employed using the "select case" procedure on SPSS V.21 to select 287 samples. Sample to variable ratio for this computed sample size was checked and was 1:21, which was acceptable for multiple linear regression analyses.

\section{Study variables}

\section{Dependent variable}

The dependent variables were overall HRQOL and each of the four domains calculated using the 24-item WHOQOL-BREF questionnaire out of 1-100 treated as continuous outcome. The WHOQOL-BREF was adopted from the validated $\mathrm{WHO}$ tool and has internal consistency that ranged from a Cronbach's alpha of 0.76 to $0.90 .^{71718}$ It has four domains (physical health, psychological, environmental and social) that denote an individual's perception of HRQOL. The physical health domain has seven items, the psychological health domain has six items, the social relationships domain has three items, and the environmental domain has eight items; it also contains one perceived quality of life item and one general health satisfaction status item. The mean score of all items in each domain was multiplied by 4 , giving a "domain raw score" (which ranged from 4 to 20) in order to make domain scores comparable. This domain raw score was linearly transformed to domain scores out of $100 .{ }^{19}$ The overall HRQOL was defined as the average of the four domain scores. HRQOL profile was categorized as low, moderate and high when the mean score was less than or equal to $45,45-65$, and greater than 65 , respectively, for all domains and overall HRQOL based on different literatures. ${ }^{19} 20$

Domain score $=($ raw score-4 $) \times(100 / 10)$. The higher the score the better the HRQOL, and the lower the score the poorer the HRQOL. The overall HRQOL was computed as the average of the scores of the four domains.

\section{Independent variables}

The independent variables were sociodemographics (sex, age, marital status, educational status and monthly income), personal factors such as body mass index
(BMI), substance consumption and enrollment in community-based health insurance. Disease-related and treatment-related factors such as treatment modality, presence of comorbidity, number of complications, and level of adherence were measured by the eight-item Morisky Medication Adherence Scale,${ }^{15}$ disease duration and blood sugar level. Interaction terms such as age with comorbidity, age with complication, and age with duration variables were created.

\section{Data quality control}

A standardized and validated WHOQOL-BREF questionnaire was prepared in English and translated to Amharic and retranslated back to English for consistency. The questionnaire was pretested on $5 \%$ (15) of the population a week before actual data collection period in Bonga Gebretsadik Shawo Hospital. The response rate during the pretest was $100 \%$, and some modifications such as correction of typing errors, data collection period and number of data collectors, and arrangement of the questionnaire (some items were reverse-coded) were done. During the pretest, the internal consistency of the tool was assessed and the Cronbach's alpha was computed (physical $=0.82$, psychological $=0.85$, environmental $=0.79$ and social $=0.72$ ), which was acceptable for this population.

Data were collected by trained data collectors. Data collectors strictly followed for redundancy of interview.interviewed medical record numbers were separetly coded for the purpose of not to be interviewed repeatdly. At the end of each data collection day, questionnaires were checked by supervisors for completeness. There was weekly discussion with data collectors and supervisors.

\section{Data analysis procedures}

Data were coded, recoded, cleaned and explored to identify outliers, missing values and inconsistencies. The coded data were checked for completeness and entered into EpiData V.3.1 and analyzed by SPSS V.21. In the descriptive analysis, the mean with SD frequency and percentages were calculated.

For the purpose of this analysis, dummy variables (for $\mathrm{k}$ categories, k-1 dummy variable) were created for categorical variables such as educational status, marital status, occupational status, treatment modality, adherence level and number of complications. The responses of reverse-coded items were converted to a positive scale by subtracting each item score from 6 (because the scale was 1 up to 5) in SPSS V.21 in order to be interpreted as higher scores have higher outcome. Linearity assumptions were checked by scatter plot, homogeneity of variances was checked by scatter plots, and there was no heteroscedasticity/no clear pattern on scatter plot. Skewness that ranged in between \pm 1 was taken as normally distributed; except for the environmental domain, all variables satisfied normality assumptions. The environmental domain did not satisfy normality assumption, so to normalize 


\begin{tabular}{llll}
\hline \multicolumn{3}{l}{ Table 1} & \multicolumn{3}{l}{ Characteristics of study participants (N=267) } \\
\hline Variables & Category & Frequency (n) & Percent \\
\hline $\begin{array}{llll}\text { Educational } \\
\text { status }\end{array}$ & $\begin{array}{l}\text { None at all } \\
\text { Primary }\end{array}$ & 51 & 19.1 \\
& $\begin{array}{l}\text { education } \\
\text { completed }\end{array}$ & & 34.8 \\
& $\begin{array}{l}\text { Secondary } \\
\text { education }\end{array}$ & 80 & \\
& $\begin{array}{l}\text { completed } \\
\text { Tertiary and }\end{array}$ & 43 & 30 \\
& above & & \\
Marital status & Currently & 214 & 16.1 \\
& married & & 80.15 \\
& Others* & 53 & 19.85 \\
Current & Yes & 44 & 16.5 \\
substance use & No & 223 & 83.5 \\
Enrollment in & Yes & 44 & 16.5 \\
CBHI & No & 223 & 83.5 \\
\hline
\end{tabular}

${ }^{*}$ Currently not married, divorced and widowed.

$\mathrm{CBHI}$, community-based health insurance.

we used square root transformation. Durbin-Watson of 1.5-2.5 was taken as independent observations.

Multicollinearity was checked and the maximum variable inflation factor reported was 1.54 , which indicates that there was no multicollinearity threat. Interaction terms were created and they were all not significant.

Simple and multivariable linear regressions were fitted for all four domains and overall HRQOL to identify associated variables with each domain and overall HRQOL. For the goodness of model fit, all linear regression assumptions, adjusted R-squared, overall $F$-test, residual plots, SEs and outliers were considered. According to these parameters the fitted models were good of fit to explain outcome variables. Variables with a $p$ value less than 0.25 during the simple linear regression were selected for multivariable linear regression. To overcome the disadvantages of forward selection and backward elimination, a stepwise variable selection method was used to identify independently associated variables. A $p$ value less than 0.05 was considered as independently associated factor for multivariable linear regressions.

\section{RESULTS}

\section{Characteristics of study participants}

From a total sample of 287 study participants, 267 participated in the study, giving a response rate of $93 \%$. A little over half of the participants $(147,55.1 \%)$ were female, and the mean age was $45 \pm 9.84$ years. Majority $(214,80.1 \%)$ of the study participants were married. The average estimated monthly income was $1136 \pm 609.60$ (SD) Ethiopian birr (table 1).

The mean BMI and fasting blood glucose level of the study participants were $23.84 \mathrm{~kg} / \mathrm{m}^{2} \quad(\mathrm{SD} \pm 3.70)$ and $139.71 \mathrm{mg} / \mathrm{dL}(\mathrm{SD} \pm 40)$, respectively. The median duration of the disease of the study participants was 5 years (1-14 years). Majority of the study participants $(163,63.3 \%)$ were taking oral hypoglycemic therapy, 56 (21\%) were on both oral hypoglycemic agent and insulin therapy, and the rest $(42,15.70 \%)$ were currently on insulin therapy. From the total interviewed study subjects, $91(34.10 \%)$ developed long-term diabetic complications and $98(36.70 \%)$ of them were comorbid with different chronic diseases. The current study revealed that 124 (46.4\%) of the study participants were highly adherent, followed by $75(28.10 \%)$ who were medium adherent and the rest were low adherent.

\section{HRQOL among adult patients with type II diabetes}

Around $143(53.6 \%)$ of the respondents scored below the mean in overall HRQOL. Among the four domains of HRQOL, respondents scored highest in the social domain (53.68 \pm 17.5$)$. The minimum and maximum mean scores of the study participants in overall HRQOL were 18.15 and 81.77 , respectively (table 2 ).

\section{Self-rated perceived quality of life and health satisfaction among adult patients with type II diabetes attending the Mizan Tepi University Teaching Hospital}

Study participants were asked to provide their perception on their HRQOL and health satisfaction. Based on their perception, around one-third $(33.7 \%)$ reported that their HRQOL was good, followed by 77 (28.8\%) reporting neither good nor poor. With regard to perceived satisfaction of their health, $86(32.2 \%)$ were satisfied with their health and $14(5.2 \%)$ were very dissatisfied with their health (table 3 ).

Table 2 Profile of health-related quality of life among adult patients with type II diabetes attending the Mizan Tepi University Teaching Hospital ( $\mathrm{N}=267), 2018$

\begin{tabular}{llllll}
\hline Domains & Minimum & Maximum & Mean & SD & $\begin{array}{c}\text { \% of participants who } \\
\text { scored below the mean }\end{array}$ \\
\hline Physical health & 10.71 & 96.43 & 49.10 & 18.14 & 49.10 \\
Psychological & 8.33 & 91.67 & 53.51 & 19.82 & 51.70 \\
Environmental & 15.63 & 96.88 & 49.72 & 16.09 & 52.10 \\
Social relationship & 16.67 & 91.67 & 53.68 & 17.50 & 54.00 \\
Overall & 18.15 & 81.77 & 51.50 & 15.78 & 53.60 \\
\hline
\end{tabular}


Table 3 Self-rated perceived quality of life and perceived health satisfaction among adult patients with type II diabetes attending the Mizan Tepi University Teaching Hospital, 2018

\begin{tabular}{lll}
\hline & $\begin{array}{l}\text { Frequency } \\
\text { (N=267) }\end{array}$ & Percent \\
\hline $\begin{array}{l}\text { Perceived quality of life } \\
\text { Very poor }\end{array}$ & 20 & 7.5 \\
\hline Little & 37 & 13.9 \\
\hline Neither poor nor good & 77 & 28.8 \\
\hline Good & 90 & 33.7 \\
\hline Very good & 43 & 16.1 \\
\hline $\begin{array}{l}\text { Perceived health satisfaction } \\
\text { Very dissatisfied }\end{array}$ & 14 & 5.2 \\
\hline $\begin{array}{l}\text { Dissatisfied } \\
\text { Neither dissatisfied nor }\end{array}$ & 41 & 15.4 \\
\hline satisfied & 81 & 30.3 \\
\hline Satisfied & 86 & 32.2 \\
\hline Very satisfied & 45 & 16.9 \\
\hline
\end{tabular}

Factors associated with domains of HRQOL and overall HRQOL among adult patients with type II diabetes by multiple linear regression models

Based on a multivariable linear regression analysis fitted for physical health domain, about $47.9 \%$ of the total variation in physical health domain was explained by variables in the model. Duration of disease $(\beta=-1.50)$, fasting blood sugar $(\beta=-0.08)$, being comorbid $(\beta=-5.86)$, and being diagnosed with two or more complications $(\beta=-11.45)$ were inversely associated with physical health domain (table 4).

About $40.6 \%$ of the total variation in environmental domain of HRQOL among adult patients with type II diabetes was explained by variables in the model, and it was $41.7 \%$ for the social domain (table 4 ).

\section{DISCUSSION}

This study tried to assess the overall HRQOL profile with its domains and associated factors among patients with diabetes. According to this finding, the overall mean HRQOL among study participants was moderate $(51.50 \pm 15.78)$ when compared with other findings. ${ }^{19} 20$ A study in Ghana has also reported comparable level of HRQOL among patients with type II DM, at $56.19 \pm 8.23 .{ }^{16}$

Type II diabetes impaired all domains of HRQOL of the study participants, but physical health was the most affected domain $(49.10 \pm 18.14)$. Studies done in Mexico and Ghana reported consistent results, showing that the physical domain of HRQOL of patients with type II diabetes was mostly affected. ${ }^{16}{ }^{21}$ This consistency could be justified by diabetes manifesting more physically than others such as psychological, environmental and social relationship domains. ${ }^{21}$ This could also be explained by patients with type II diabetes having higher rates of
Table 4 Multivariable linear regression model showing independently associated factors with domains of $\mathrm{HRQOL}$ and overall HRQOL among adult patients with type II diabetes attending the Mizan Tepi University Teaching Hospital, 2018

\begin{tabular}{llll}
\hline HRQOL and its & $\begin{array}{l}\text { Unstandardized } \\
\text { coefficient }(\beta)\end{array} \quad(95 \% \mathrm{Cl}$ for $\beta)$ & P value
\end{tabular}

Physical health domain $(\mathrm{N}=267)$

\begin{tabular}{|c|c|c|c|}
\hline Constant & 93.26 & (83.94 to 102.57 ) & $<0.001$ \\
\hline Age & -0.48 & $(-0.68$ to -0.30$)$ & $<0.001$ \\
\hline $\begin{array}{l}\text { Duration of } \\
\text { disease }\end{array}$ & -1.50 & $(-2$ to -0.92$)$ & $<0.001$ \\
\hline $\begin{array}{l}\text { Fasting blood } \\
\text { sugar }\end{array}$ & -0.08 & $(-0.12$ to -0.04$)$ & $<0.001$ \\
\hline $\begin{array}{l}\text { Comorbidity } \\
\text { status }\end{array}$ & -5.86 & $(-9.43$ to -2.29$)$ & 0.001 \\
\hline \multicolumn{4}{|l|}{$\begin{array}{l}\text { Number of } \\
\text { complications }\end{array}$} \\
\hline \multicolumn{4}{|l|}{ No complication* } \\
\hline 1 complication & -0.99 & ( -4.88 to 2.89$)$ & 0.62 \\
\hline$\geq 2$ Complications & -11.45 & $(-17.40$ to -5.50$)$ & 0.001 \\
\hline \multicolumn{4}{|c|}{ Psychological domain ( $\mathrm{N}=267)$} \\
\hline Constant & 120.58 & (105.22 to 135.95 ) & $<0.001$ \\
\hline Age & -0.43 & $(-0.64$ to -0.21$)$ & $<0.001$ \\
\hline $\begin{array}{l}\text { Duration of } \\
\text { disease }\end{array}$ & -1.67 & $(-2.32$ to -1.01$)$ & $<0.001$ \\
\hline $\begin{array}{l}\text { Fasting blood } \\
\text { sugar }\end{array}$ & -0.11 & $(-0.16$ to -0.06$)$ & $<0.001$ \\
\hline
\end{tabular}

\section{Number of}

complications

No complication*

1 complication $\quad-1.69 \quad(-6.10$ to 2.72$) \quad 0.45$

$\geq 2$ Complications $-9.94 \quad(-16.68$ to -3.19$) \quad 0.004$

Body mass index $-0.96 \quad(-1.49$ to -0.43$)<0.001$

Square root of environmental domain $(\mathrm{N}=267)$

\begin{tabular}{|c|c|c|c|}
\hline Constant & 10.24 & (9.30 to 11.18 ) & $<0.001$ \\
\hline Age & -0.023 & $(-0.036$ to -0.01$)$ & 0.001 \\
\hline $\begin{array}{l}\text { Duration of } \\
\text { disease }\end{array}$ & -0.096 & $(-0.14$ to -0.06$)$ & $<0.001$ \\
\hline Comorbidity & -0.28 & $(-0.52$ to -0.04$)$ & 0.024 \\
\hline $\begin{array}{l}\text { Fasting blood } \\
\text { sugar }\end{array}$ & -0.004 & $\begin{array}{l}(-0.007 \text { to } \\
-0.002)\end{array}$ & 0.002 \\
\hline Body mass index & -0.04 & $\begin{array}{l}(-0.072 \text { to } \\
-0.008)\end{array}$ & 0.016 \\
\hline
\end{tabular}

Social relationship domain $(\mathrm{N}=267)$

\begin{tabular}{lrll} 
Constant & 111.65 & $(97.18$ to 126.11$)$ & $<0.001$ \\
Age & -0.56 & $(-0.76$ to -0.35$)$ & $<0.001$ \\
$\begin{array}{l}\text { Duration of } \\
\text { disease }\end{array}$ & -1.56 & $(-2.20$ to -0.93$)$ & $<0.001$ \\
$\begin{array}{l}\text { Fasting blood } \\
\text { sugar }\end{array}$ & -0.09 & $(-0.13$ to -0.04$)$ & $<0.001$ \\
$\begin{array}{l}\text { Body mass index } \\
\text { Dod }-0.53\end{array}$ & $(-1$ to -0.01$)$ & 0.045 \\
\hline verall HRQOL $(\mathrm{N}=267)$ & &
\end{tabular}

Continued 


\begin{tabular}{|c|c|c|c|}
\hline $\begin{array}{l}\text { HRQOL and its } \\
\text { domain }\end{array}$ & $\begin{array}{l}\text { Unstandardized } \\
\text { coefficient }(\beta)\end{array}$ & $(95 \% \mathrm{Cl}$ for $\beta)$ & $P$ value \\
\hline Constant & 106.38 & (95.13 to 117.63 ) & $<0.001$ \\
\hline Age & -0.42 & (0.58 to -0.26$)$ & $<0.001$ \\
\hline $\begin{array}{l}\text { Duration of } \\
\text { disease }\end{array}$ & -1.45 & $(-1.93$ to -0.98$)$ & $<0.001$ \\
\hline $\begin{array}{l}\text { Fasting blood } \\
\text { sugar }\end{array}$ & -0.08 & $(-0.12$ to -0.05$)$ & $<0.001$ \\
\hline Comorbidity & -3.25 & $(-6.18$ to -0.33$)$ & 0.029 \\
\hline \multicolumn{4}{|l|}{$\begin{array}{l}\text { Number of } \\
\text { complications }\end{array}$} \\
\hline \multicolumn{4}{|l|}{ No complication* } \\
\hline 1 complication & 0.34 & $(-2.86$ to 3.53$)$ & 0.84 \\
\hline$\geq 2$ Complications & -6.61 & $(-11.49$ to -1.73$)$ & 0.008 \\
\hline Body mass index & -0.61 & ( -1 to -0.22$)$ & 0.002 \\
\hline
\end{tabular}

${ }^{*}$ Reference category=not comorbid and no complication of diabetes mellitus. VIFmax $=1.5$. $P$ value for $F$-test in all domains and overall HRQOL was $<0.001$.

HRQOL, health-related quality of life; VIF, variable inflation factor.

complications which can affect their physical ability to do regular activities. This study revealed that from all domains, the social domain was the least affected, which is similar to studies done in Malaysia, Ghana and Iran. ${ }^{1622} 23$ This could be due to social support they received from their families and friends. In contrast, a study done in Poland ${ }^{24}$ showed that relatively social domain score was the lowest, and this could be due to sociocultural variations and lifestyle differences.

Age has an inverse relation with all aspects of HRQOL in this study, which was a finding similar to studies conducted previously. In line with the current finding, studies conducted in Indonesia, Serbia, Botswana and Iran revealed that age was inversely related with HRQOL. ${ }^{9} 232526$ The current study revealed that age was inversely associated with the psychological domain of HRQOL (95\% CI for $\beta-0.67$ to -0.24 ). Such findings may reflect that younger people are more likely to enjoy better health than the elderly.

In addition to this, aging may decline the physiological system, which could limit the different activities of the body. This study was inconsistent with a study done in Egypt which reported that a 1-year increase in age will increase the psychological domain by $0.34 .{ }^{19}$ This difference could be because as age increases, patients have fewer responsibilities to think about, such as with regard to work and their families, compared with younger patients. ${ }^{19}$ This study revealed that the duration of disease has inverse relation with all domains of HRQOL. This finding is in line with a study conducted using the Short-Form 36 instrument in Ethiopia which showed that longer duration of illness and comorbidity were important predictors of impaired HRQOL. ${ }^{14}$

This finding is in agreement with studies done in Serbia and Malaysia which showed that longer disease duration has a negative impact on HRQOL. ${ }^{92}$ This may be due to long disease duration increase renal, eye, neural and other complications of diabetes, and being dependent on medications for a long time which may cause side effects, which then contributes to impairment in HRQOL.

In contrast, the study done in Nigeria showed that disease duration has direct/positive association with HRQOL, and a study in Nepal showed that individuals with disease duration greater than 10 years had improved physical and social domains than those with less than 10 years. ${ }^{27}$ Individuals with longer duration of the disease has direct association with HRQOL due to thier long term exprience for information, got support from their families and friends to modify their life style than those with short disease duration.

The current study also showed that fasting blood sugar was inversely associated with almost all aspects of HRQOL except social domain. This result is in agreement with studies done in Mexico, Serbia and Egypt which explained that fasting blood sugar level was significantly associated with impaired HRQOL in patients with type II diabetes. ${ }^{9}{ }^{19} 21$ This consistency could be due to high blood glucose manifesting as hyperglycemic symptoms such as polyuria, polydipsia, generalized weakness, dependency on medications and sleeping disturbances, which may impair HRQOL.

This can also be justified as those who have higher blood glucose need different healthcare services, are unable to perform their routine activities and are unable to participate in different activities, contributing to impaired HRQOL.

This result showed comorbidity was associated inversely with physical domain (95\% CI for $\beta-9.43$ to -2.30 ) and the transformed square root of environmental domain (95\% CI for $\beta-0.52$ to -0.037 ) and overall HRQOL (95\% CI for $\beta-6.19,-0.33)$. This result was consistent with previous studies done in Mexico, Iran (for physical domain $[\beta=-5.8]$ ) and Malaysia (for physical domain $[\beta=-3.14]) .^{1421-23}$ This result revealed that the presence of comorbidity was negatively associated with overall HRQOL, which was similar to the study done in USA using a health utility index tool showing that comorbid patients were more likely to have impaired HRQOL $(p<0.05){ }^{28}$ This could be justified by their dependency on many different medications, the money much needed to afford these drugs and the demand for healthcare services since they were comorbid, contributing to impairment of the physical health and environmental health domains. This could also be due to the contributions of different chronic diseases in patients with diabetes and the side effects/drug interactions of the different drugs, which impair all aspects of HRQOL.

According to the results of this study, BMI had inverse association with psychological, environmental and social domains and overall HRQOL. In this study obesity reduces physical domain, which was comparable with the studies done in Egypt $(\mathrm{p}<0.001)^{19}$ and in Mexico showing that the physical component of HRQOL of obese 
patients with DM was worse. ${ }^{21}$ The study done in Poland had consistent result and showed that incorrect BMI has a negative influence on the psychological, environmental and social domains of HRQOL. ${ }^{24}$ In the current study BMI was inversely associated with overall HRQOL among patients with type II DM, and this result was supported by the study done in Poland. ${ }^{24}$ This similarity could be explained by their difficulty in moving around and due to their inability to accept their own body appearance. However, these findings were inconsistent with the results conducted in Botswana which showed that there was no significant association between BMI and HRQOL. This discrepancy could be justified by the different tool used; they used the Short-Form 12 tool. $^{26}$

This result showed that the presence of two or more complications was inversely associated with physical and psychological domains and overall HRQOL, which was similar to previous studies done in Kenya and USA showing that the number of complications was negatively associated with all aspects of HRQOL except for the social and environmental domains. ${ }^{28}{ }^{29}$ This finding was also in agreement with a study done in Saudi Arabia which reported that the presence of two or more complications has a negative association with almost all domains of HRQOL. ${ }^{30}$

\section{Strengths of the study}

We used internationally valid and consistent tool to measure health-related quality life. The current study considered the outcome variable as continuous, which might minimize misclassification bias. On top of this, our study assessed the impact of BMI and the number of complications on HRQOL, which has not been addressed by other studies.

\section{Limitations of the study}

Considering the different educational level of respondents, we used face-to-face interview, which may lead to social desirability bias and could overestimate the result. On top of this, there might be recall bias, which might overestimate or underestimate the result. An ample of factors are likely to influence the HRQOL of the participants included in this study, for instance loss of relatives due to death, trauma and other factors, which may cause depression and contribute to impaired HRQOL.

\section{CONCLUSION}

This study revealed that HRQOL among adult patients with type II DM was relatively moderate in all domains and in overall HRQOL. The current study revealed that the physical domain was the most affected domain. Duration of disease, age and fasting blood sugar were associated with decreased HRQOL in all domains and overall HRQOL. Age, BMI, presence of documented comorbidity, being diagnosed with two or more complications, duration of disease and blood glucose level were inversely associated with overall HRQOL.
Acknowledgements We would like to thank the University of Jimma for ethical approval. We acknowledge Mizan Aman College of Health Science for their financia support, and we also like to extend our appreciation to the data collectors and the study participants for their devoted cooperation.

Contributors TG, AW and DA conceived of the study and were involved in the design of the study, coordination and review of the article, analysis, writing of the report, and drafting of the manuscript. All authors read and approved the final manuscript.

Funding This research work was funded by Mizan Aman Health Science College.

\section{Competing interests None declared.}

\section{Patient consent for publication Obtained.}

Ethics approval The study was approved by the ethical committee of the Institute of Public Health, College of Medicine and Health Science and University of Jimma. Before data collection, ethical clearance letter was obtained from the ethical review board of Jimma University Institute of Health. The letter was submitted to Mizan Tepi University Teaching Hospital management for permission. The letter was obtained from the medical director of the hospital and submitted to outpatient department coordinators. Respondents were informed and their oral consent was obtained. The respondents' right to refuse or withdraw from participating in the interview at any time was fully respected, and the information provided by each respondent was kept confidential by putting the collected data in a separate room.

Provenance and peer review Not commissioned; externally peer reviewed.

Data sharing statement № additional data available.

Open access This is an open access article distributed in accordance with the Creative Commons Attribution Non Commercial (CC BY-NC 4.0) license, which permits others to distribute, remix, adapt, build upon this work non-commercially, and license their derivative works on different terms, provided the original work is properly cited, appropriate credit is given, any changes made indicated, and the use is non-commercial. See: http://creativecommons.org/licenses/by-nc/4.0/.

\section{REFERENCES}

1. IDF. Atlas international diabetic Federation 2015.

2. WHO. Global report on diabetes 2016.

3. WHO, 2014. Preventing chronic diseases: a vital investment. Available from: http://www.worldlifeexpectancy.com/ethiopiadiabetes-mellitus

4. American Diabetes Association. Diagnosis and classification of diabetes mellitus. Diabetes Care 2014;37:S81-90.

5. ADA. Standards of medical care in diabetes. J Clin Appl Res Educ 2017;40:1-142.

6. WHO. Measuring quality of life 1994.

7. WHO. WHOQOL user manual Dision 1998.

8. WHO. Definition and diagnosis of DM and intermediate hyperglycemia 2005

9. Spasić A, Radovanović RV, Đorđević AC, et al. Quality of life in type 2 diabetic patients. Acta Fac Medicae Naissensis 2014;31:193-200.

10. CDC. Population assessment of health-related quality of life 2000.

11. Saleh F, Mumu SJ, Ara F. Non-adherence to self-care practices \& medication and HRQOL among T2DM. BMC Public Health 2014:1-8.

12. Al-Shehri FS. Quality of life among Saudi diabetics. J Diabetes Mellitus 2014;04:225-31.

13. WHO. Introducing the WHOQOL instruments strengths of the WHOQOL instruments 2011.

14. Muze M, Hailu E, Woldemichael K, et al. Health related quality of life and its associated factors among diabetic patients attending diabetes clinic in Jimma university teaching hospital, Ethiopia, 2014. J Diabetes Metab 2017;08:7-11.

15. Alfian SD, Sukandar H, Lestari K. Medication adherence contributes to an improved QOL T2DM patients. Diabetes Ther 2016;7:755-64.

16. Ababio GK, Bosomprah S, Olumide A, et al. Predictors of quality of life in patients with diabetes mellitus in two tertiary health institutions in Ghana and Nigeria. Niger Postgrad Med J 2017;24:48-55.

17. Tesfaye M, Olsen MF, Medhin G, et al. Adaptation and validation of the short version WHOQOL-HIV in Ethiopia. Int J Ment Health Syst 2016;10:1-10.

18. Li L, Young D, Xiao S, et al. Psychometric properties of the WHO quality of life questionnaire (WHOQOL-100) in patients with chronic diseases and their caregivers in China. Bull World Health Organ 2004:82:493-502.

19. Ibrahim Feta. Physical and psychological health domains of QOL in relation to clinical factors of diabetes mellitus in Egypt. Int Res $J$ Med Med Sci 2016;4:7-16. 
20. Bani-Issa W. Evaluation of the health-related quality of life of Emirati people with diabetes: integration of sociodemographic and diseaserelated variables. East Mediterr Health J 2011;17:825-30.

21. Doubova SV, Mino-León D, Pérez-Cuevas R. Linking quality of healthcare and health-related quality of life of patients with type 2 diabetes: an evaluative study in Mexican family practice. Int J Qual Health Care 2013;25:664-72.

22. Chew BH, Mohd-Sidik S, Shariff-Ghazali S. Negative effects of diabetes - related distress on HRQOL : an evaluation among the adult T2DM in 3 primary healthcare clinics in Malaysia. Health Qual Life Outcomes 2015;13:187.

23. Didarloo A, Alizadeh M. Health-related quality of life and its determinants among women with diabetes mellitus: a crosssectional analysis. Nurs Midwifery Stud 2016;5:e28937.

24. Fal AM, Jankowska B, Uchmanowicz I, et al. Type 2 diabetes quality of life patients treated with insulin and oral hypoglycemic medication. Acta Diabetol 2011;48:237-42.
25. Perwitasari DA, Urbayatun S. Treatment adherence and quality of life in diabetes mellitus patients in Indonesia. Sage Open 2016;6:215824401664374.

26. Mutashambara Geta. HRQOL factors among patients with DM in Botswana. Alexandria J Med 2018;54:111-8. doi:.

27. Mishra SR, Sharma A, Bhandari PM. Depression and HealthRelated Quality of Life among Patients with Type-II Diabetes Mellitus : A Cross-Sectional Study in Nepal. PLoS One 2015;74:1-13.

28. Wexler DJ, Grant RW, Wittenberg E, et al. Correlates of health-related quality of life in type 2 diabetes. Diabetologia 2006;49:1489-97.

29. Genga EK, Otieno CF. Assessment of the perceived QOL of NIDDM attending the DM clinic in Kenyatta National Hospital. IOSR J. Pharm 2014;4:15-21.

30. Hayek Ea. Factors associated with HRQOLamong Saudi patients withT2DM. Diabetes Metaboism J 2014:220-9. 